\title{
Jet Exit Rig Six Component Force Balance
}

\author{
Raymond Castner ${ }^{1}$, John Wolter ${ }^{1}$, Mark Woike ${ }^{2}$ \\ NASA Glenn Research Center, Cleveland, Ohio, 44135 \\ Dennis Booth ${ }^{3}$, David King ${ }^{4}$ \\ Triumph Aerospace, Force Measurement Systems, San Diego, CA, 92121
}

\begin{abstract}
A new six axis air balance was delivered to the NASA Glenn Research Center. This air balance has an axial force capability of $\mathbf{8 0 0}$ pounds, primary airflow of 10 pounds per second, and a secondary airflow of 3 pounds per second. Its primary use was for the NASA Glenn Jet Exit Rig, a wind tunnel model used to test both low-speed, and high-speed nozzle concepts in a wind tunnel. This report outlines the installation of the balance in the Jet Exit Rig, and the results from an ASME calibration nozzle with an exit area of 8 squareinches. The results demonstrated the stability of the force balance for axial measurements and the repeatability of measurements better than \pm 0.20 percent.
\end{abstract}

\section{Introduction}

The Jet Exit Rig (JER) was designed for use at the NASA Glenn Research Center in its propulsion wind tunnels, such as the 8-foot by 6-foot Supersonic Wind Tunnel ${ }^{1}$. It was first designed for hypersonic nozzle testing, and later for supersonic nozzle testing. The current configuration allows low bypass turbojet engine simulation with engine core flow temperatures up to $2000 \mathrm{R}$ and engine bypass flow at $530 \mathrm{R}$. Core mass flow rates with the new force balance are $10 \mathrm{lbm} / \mathrm{sec}$ and bypass mass flow rates are $3 \mathrm{lbm} / \mathrm{sec}$. The rig was designed as a low cost alternative to perform ground testing of advanced nozzle concepts, as compared to a flight test or a full scale jet engine test. This configuration allows scale model testing with nozzles having a maximum exit area of 8 sq-in. The two streams could be used as a dual flow turbojet engine flow, or as primary and secondary airflow where secondary air could be used for cooling or fluidic thrust vectoring technologies.

This report describes the validation test for the 6-axis force balance as used on the Jet Exit Rig (JER) at the NASA Glenn Research Center. The purpose of the test was to demonstrate that the balance is capable of repeatable measurements and to identify where improvements can be made to balance performance. Information includes (1) the design of the 6-axis balance, (2) a description of the balance and the JER, and (3) the installation in the Propulsion Systems Lab with an 8 sq-in ASME nozzle. In addition, thrust measurements with the ASME nozzle are provided.

\section{Force Balance}

The design of the flow though air balance provides high pressure air while measuring six axes of thrust measurement for the Jet Exit Rig, as displayed in Fig. 1. Its design is a force type balance with an integral air system that is installed in the center hole through the inner non-metric rod of the balance (Fig. 2). The air passes through the center in an air tube and then through opposing high pressure welded bellows that mount to the outside of the tube. The bellows bridge the non-metric inner rod and the metric outer shell. The air system is pressurized and the tare effects are characterized with additional sensitivity coefficients. The flexible welded bellows allow the system to have consistent performance over a range of loads and pressure settings. The bellows are vertically opposed to each other to cancel the momentum of turning air from an axial to a vertical direction. The air is routed around the outer diameter of the balance, with a second 90-degree turn to turn the air forward into a plenum chamber. The multiple 90-degree turns are intended to cancel the momentum effects of the high pressure and high volume airflow. The design of this system allows multiple air passages to be installed co-axially on the balance. Multiple air systems allow for simulation of jet engine core and bypass flow, where the effects are fully calibrated.

\footnotetext{
${ }^{1}$ Aerospace Engineer, Inlet and Nozzle Branch, 21000 Brookpark Road, and AIAA Associate Fellow.

${ }^{2}$ Electronics Engineer, Optical Instrumentation and NDE Branch, 21000 Brookpark Road.

${ }^{3}$ Operations Manager- Force Measurement Systems, Triumph Aerospace Systems NN (AeroFMS.COM)

7340 Trade Street Suite D, San Diego CA 92121 drbooth @ triumpgroup.com 858-537-2020 x-301

${ }^{4}$ Design Manager- Force Measurement Systems, TAS-NN, 7340 Trade Street Suite D, San Diego CA 92121
} 
The balance is calibrated as a complete system, where a full calibration was accomplished for the balance with no pressure applied in the air systems and then repeated with each of the air systems pressurized. The resulting calibration was processed for each air system and coefficients for each system were optimized to develop a matrix over the entire operating range. The calibration of the air balance with three separate air systems was completed with an updated process utilizing the Automatic Balance Calibration System ${ }^{2}$ (ABCS) located at Triumph Aerospace Systems (Fig. 3). Data processing was derived from the AIAA 6x96 matrix format ${ }^{3}$, tailored to add terms for the pressure effects and a separate matrix to account for the tare due to the pressurization of each air system.

\section{Jet Exit Rig}

The NASA Glenn Jet Exit Rig (JER) is designed for testing scale models of low speed and high speed exhaust nozzle concepts. This section describes physical characteristics of the NASA Glenn Jet Exit Rig (JER), with maximum operating Nozzle Pressure Ratio (NPR) of 6.8 at a temperature of 530 R, and NPR of 4.4 at 2000 R. The Jet Exit Rig is typically installed at the NASA Glenn Research Center in the 8 foot by 6 foot Supersonic Wind Tunnel ${ }^{1}$, the 9 foot by 15 foot Low Speed Wind Tunnel ${ }^{4}$, and the Nozzle Acoustic Test Rig ${ }^{5}$.

\section{III.A. Non-metric components}

The JER is mounted on a 45 degree angled support strut which is two inches thick and 64 inches long, with 8-inch long leading and trailing edge fairings (Fig. 1). Compressed air at 450 psig is supplied through ten passages, each 1.12 inch diameter. These air passages are divided into two distinct airflows, with 5 passages each. Each set is combined into a plenum at the top of the strut and housed in an aerodynamic bullet nose and side-plates. Fuel, water, and instrumentation lines are routed through the leading and trailing edge fairings; then around the air plenums beneath the side-plates. Fuel capabilities are $0.22 \mathrm{lbm} / \mathrm{sec}$ of gaseous hydrogen at 1100 psig through a 3/8" heavy wall stainless steel tube. Cooling water capabilities are 30 GPM at 250 psig, supplied through 4 sets of 3/8" reinforced nylon tubing.

\section{III.B. Axisymmetric Metric Components}

\section{III.B.1. Thrust Measurement Balance}

The JER contains a six component thrust measurement balance, with load limits as listed in Table 1, which represent the maximum design loads that should be applied. The balance is mounted downstream of the air plenums and provides internal routing of $450 \mathrm{psig}$ air passages and gaseous hydrogen fuel. Instrumentation and cooling water are routed outside of balance, inside of aerodynamic side-plates.

The transition section, located upstream of the force balance, directs the two parallel air passages into a coannular core and bypass arrangement, simulating a jet engine. Both air flows remain separate and can be controlled independently with facility valves. In addition, gaseous hydrogen fuel is routed through the center of the core flow to the combustor module.

\section{III.B.2. Combustor Module}

The combustor module is composed of two parts, a hydrogen fuel injector and the hydrogen combustor, and is shown in Figure 4. The hydrogen fuel injector is fabricated from 321 stainless steel. Gaseous hydrogen fuel enters the injector from the center and is routed outward at $0^{\circ}, 90^{\circ}, 180^{\circ}$ and $270^{\circ}$. Fuel is spread through three annular rings with injector passages into the core flow. The fuel and air mixture is ignited with a high energy spark, generated externally and supplied through a tube into the hydrogen manifold. The hydrogen combustor is also fabricated from 321 stainless steel, and provides mixing for the hydrogen and air mixture. The chamber is lined with a hastelloy-x sleeve heat shield. Scalloped baffles are placed in the core flow to enhance mixing and burning. All Orings and seals upstream of the combustor are silicone with a temperature limit of $550 \mathrm{~F}$. Critical seals are instrumented with thermocouples, and continuous operation above $2000 \mathrm{R}$ is often limited to10 min duration. Seals downstream of the combustor are metal C-rings. Cooling water is circulated outside the combustor liner at a rate of 8-20 GPM, depending on operating temperature. Inlet and outlet temperature conditions are used to set water flow rates. Maximum water exit temperature is $120 \mathrm{~F}$. Bypass airflow is allowed to flow around the combustion chamber with minimal restriction and no heating.

\section{III.B.3. Flow Conditioning and Measurement Station}

The flow conditioning and measurement station is fabricated from 321 stainless steel. Two choke plates provide a large pressure drop, flow straightening, and improved temperature uniformity. Each hastelloy-x plate is 0.75 inch thick, where the first choke plate has a flow area of $4.2 \mathrm{in}^{2}$ and the second choke plate is $7.0 \mathrm{in}^{2}$. 
Temperature and pressure rakes in the core flow are also fabricated from hastelloy-x. Temperatures are measured with 11 platinum-rhodium thermocouples and pressures are measured with 10 total pressure tubes. Rakes in the bypass flow are 321 stainless steel, while temperatures are measured with 4 chromel-alumel thermocouples.

\section{III.B.4. ASME Nozzle}

The nozzle connect station is used to attach test nozzles of approximately $8 \mathrm{in}^{2}$ nominal exit area, for core flow only, or $13 \mathrm{in}^{2}$ nominal exit area for mixed hot core and bypass flow. An ASME ${ }^{6}$ contoured nozzle with an exit area of $8 \mathrm{in}^{2}$ (Fig. 5) was used for this test. Instrumentation included an array of 24 static pressures on the base of the nozzle to measure and calculate base drag induced by airflow. The maximum nozzle pressures are 65 psia at $2000 \mathrm{R}$, and $100 \mathrm{psia}$ at ambient temperature conditions.

\section{Force Balance Results}

The purpose of the test was to demonstrate the repeatability of the measurements and to identify where improvements could be made to the performance of the balance. The JER tests occurred across 10 separate runs on 8/30/2011, 9/7/2011, and 9/9/2011. The test occurred in the Propulsion Systems Lab ${ }^{7}$, as seen in Fig. 6 and Fig. 7. Nozzle thrust measurement data were collected with the 8sq-in ASME nozzle at nozzle pressure ratios (NPR) from 1.5 to 3.75 , where nozzle mass flow ranged from a $3.9 \mathrm{lbm} / \mathrm{sec}$ to $9.8 \mathrm{lbm} / \mathrm{sec}$. The ASME nozzle calibration was run at ambient temperature conditions.

ASME nozzle results for axial force are reported, and displayed in Fig. 8, where the thrust coefficient, $\mathrm{C}_{\mathrm{fg}}$, is provided for NPRs from 1.5 to 3.75 . Thrust coefficient $\left(\mathrm{C}_{\mathrm{fg}}\right)$ is defined as the measured thrust divided by the ideal thrust where ideal thrust is based on exit velocity ${ }^{8}$. The predicted $\mathrm{C}_{\mathrm{fg}}$ was computed per industry standard as described by Mikkelson ${ }^{9}$, and is included in Fig. 5. For data collected at choked flow conditions, uncorrected thrust coefficient was $1.2 \%$ to $2.1 \%$ greater than predicted, and was repeatable to $+/-0.2 \%$.

Corrected values for $\mathrm{C}_{\mathrm{fg}}$ are displayed against the prediction in Fig. 8, and represent a correction using a piece-wise curve fit. This type of correction provides an indication of the overall thrust load for nozzles with equivalent exit areas of $8 \mathrm{sq}$-in. However, more work is needed to quantify momentum and pressure tare effects on the bellows air system with airflow, similar to work performed on the propulsion simulator for the NASA Langley 16-foot Transonic Wind Tunnel ${ }^{10}$. Without additional corrections, the Jet Exit Rig force balance can measure thrust differences between configurations, and can provide an estimate of thrust levels.

Nozzle discharge coefficient, $C_{D}$, is the measured mass flow divided by the ideal mass flow (Fig. 9). For the JER, the discharge coefficient was $0.5 \%$ higher than predicted. Parts to the JER were built in 1989 and have been used for numerous test programs. Use at elevated temperatures has caused distortion at the flange surfaces, and has generated leaks from the core flow passages to the bypass flow passages. These leaks affected mass flow measurements and caused the high discharge coefficients. A unified combustor and flow measurement station would reduce or eliminate leakages between the core and bypass streams.

\section{Conclusions}

A validation test was completed for the new 6-axis force balance as used on the Jet Exit Rig (JER) at the NASA Glenn Research Center. The purpose of the test was to demonstrate the repeatability of the thrust measurements and to identify balance performance improvements. The results demonstrated the stability of the force balance for axial measurements, with repeatability of measurements better than \pm 0.2 percent. The thrust coefficient was $1.2 \%$ to $2.1 \%$ greater than predicted, and the discharge coefficient was $0.5 \%$ higher than predicted. The Jet Exit Rig force balance can measure thrust differences between configurations, and provide an estimate of actual thrust levels. Recommendations are (1) to perform a CFD study on the balance air system to determine if the static pressure measurement at the required airflows is accurate, (2) test to determine the pressure and momentum tare on the balance with airflow, and (3) fabricate a unified combustor and flow measurement hardware to eliminate leakage paths and improve nozzle discharge coefficient. 


\section{Acknowledgements}

This work was funded by the NASA Fundamental Aeronautics Program, Supersonics Project, and the NASA Aeronautics Test Program (ATP) National Force Measurement Technology Capability (NFMTC) Project.

\section{References}

${ }^{1}$ Soeder, R. H., "NASA Lewis 8- by 6- Foot Supersonic Wind Tunnel Users Manual," NASA TM- 105771.

${ }^{2}$ Booth, D., King, D., Castner, R., Galway, R., "Calibration of a Six Component Air Flow through Balance, " 7th International Balance Symposium, NASA Langley 2010.

3 "Calibration and Use of Internal Strain-Gage Balances with Application to Wind Tunnel Testing," AIAA Recommended Practices document AIAA R-091-2003.

${ }^{4}$ Soeder, R. H., "NASA Lewis 9x15-Foot Low Speed Wind Tunnel User Manual," NASA TM-106247.

${ }^{5}$ Castner, R. S., "The Nozzle Acoustic Test Rig; An Acoustic and Aerodynamic Free-Jet Facility," NASA TM106495.

${ }^{6}$ ASME, "Fluid Meters, their Theory and Application," 6th ed, 1971.

${ }^{7}$ Soeder, R. H., "NASA Lewis Propulsion Systems Laboratory customer guide manual," NASA TM-106589.

${ }^{8}$ Stitt, L. E., "Exhaust Nozzles for Propulsion Systems with Emphasis on Supersonic Cruise Aircraft," NASA RP1235.

${ }^{9}$ Mikkelsen, K. L. and Brasket, R. G., "An Equation Set for ASME Nozzle Discharge and Thrust Coefficients," AIAA-2011-1265, Jan. 2011.

10 "A Users Guide to the Langley 16-foot Transonic Tunnel Complex," NASA TM-102750, Section V, pg 139.

Table 1. Force Balance Load Limits.

\begin{tabular}{|c|c|c|c|c|c|c|}
\hline & NF (lb) & PM (in-lb) & SF (lb) & YM (in-lb) & RM (in-lb) & AF (lb) \\
\hline $\begin{array}{c}\text { Test Loads } \\
70 \text { in. from BMC }\end{array}$ & 200 & 16,000 & 200 & 16,000 & $2000^{*}$ & 800 \\
\hline $\begin{array}{c}\text { Test Article } \\
200 \text { lb. at } 68 \text { in. }\end{array}$ & 200 & 13,600 & - & - & - & - \\
\hline $\begin{array}{c}\text { Rig Hardware } \\
200 \text { lb. at } 35.5 \text { in. }\end{array}$ & 200 & 7,100 & - & - & - & - \\
\hline $\begin{array}{c}\text { Un-start Loads } \dagger \\
\text { at } 40 \text { in. }\end{array}$ & 1,093 & 43,720 & 1,093 & 43,720 & $\overline{0}$ & 556 \\
\hline $\begin{array}{c}\text { Total Balance } \\
\text { Load Capacity }\end{array}$ & $1,693^{*}$ & 81,720 & 1,343 & 59,720 & $2000 * *$ & 1,356 \\
\hline
\end{tabular}

$\mathrm{BMC}=$ Balance Moment Center

$\mathrm{NF}=$ Normal Force, $\mathrm{PM}=$ Pitch Moment, $\mathrm{SF}=$ Side Force

$\mathrm{YM}=$ Yaw Moment, $\mathrm{RM}=$ Roll Moment, $\mathrm{AF}=$ Axial Force

* Minimum value, determined by the PM acting on the balance

$\uparrow$ Wind Tunnel Un-Start Loads are for the 8-foot by 6-foot Supersonic Wind Tunnel ${ }^{1}$

**nominal value, determined by the NF acting on the balance 


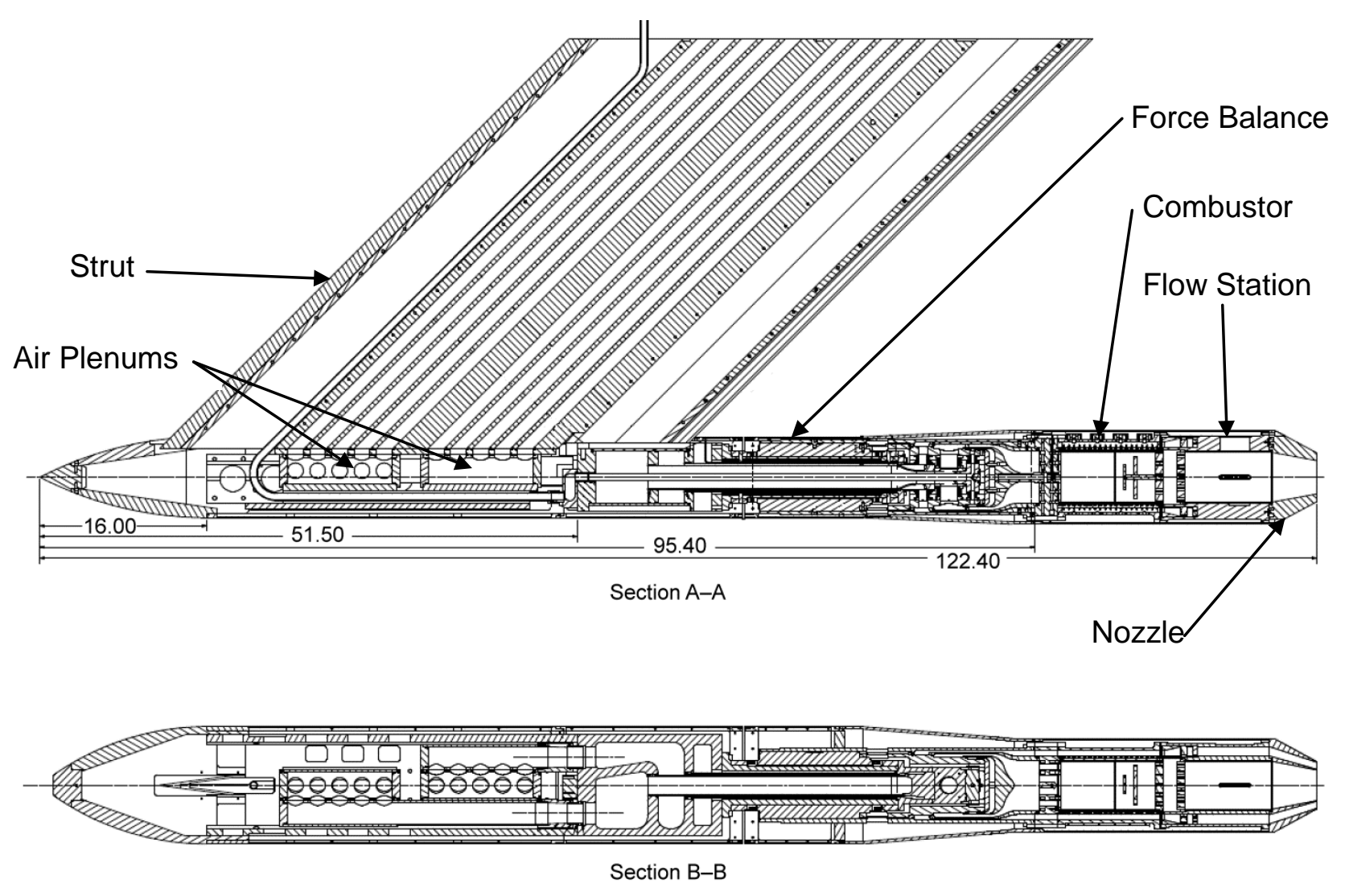

Fig 1. Jet Exit Rig Assembly.

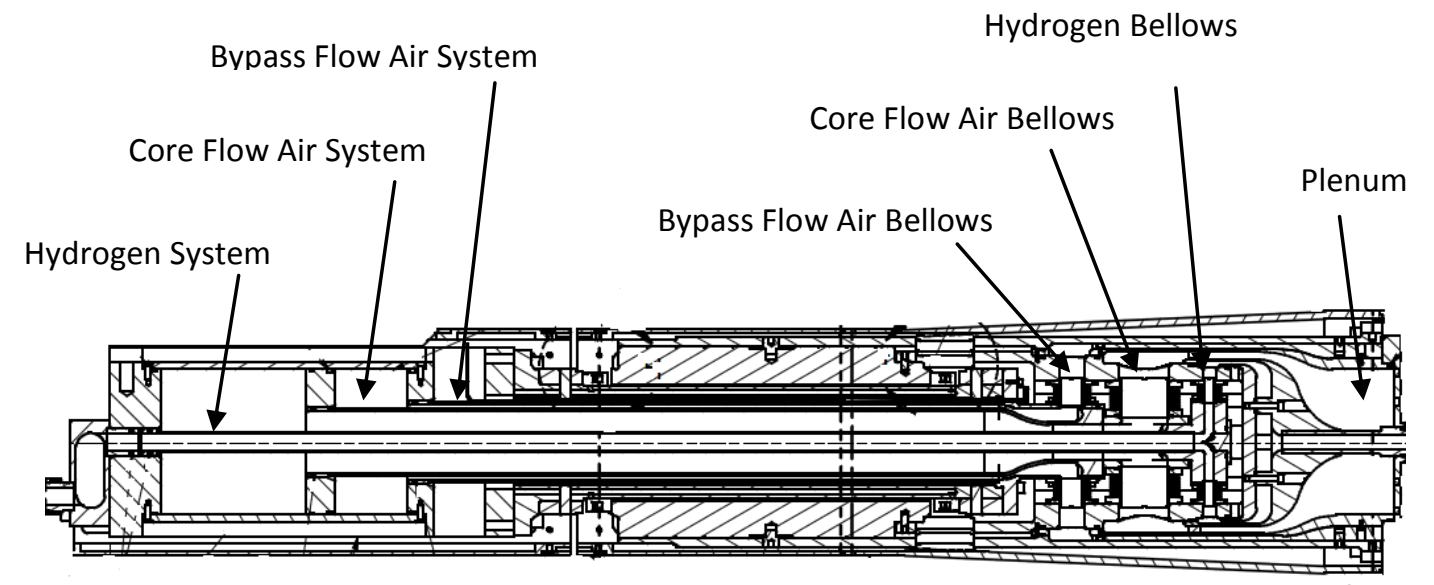

Fig 2. Jet Exit Rig Balance. 


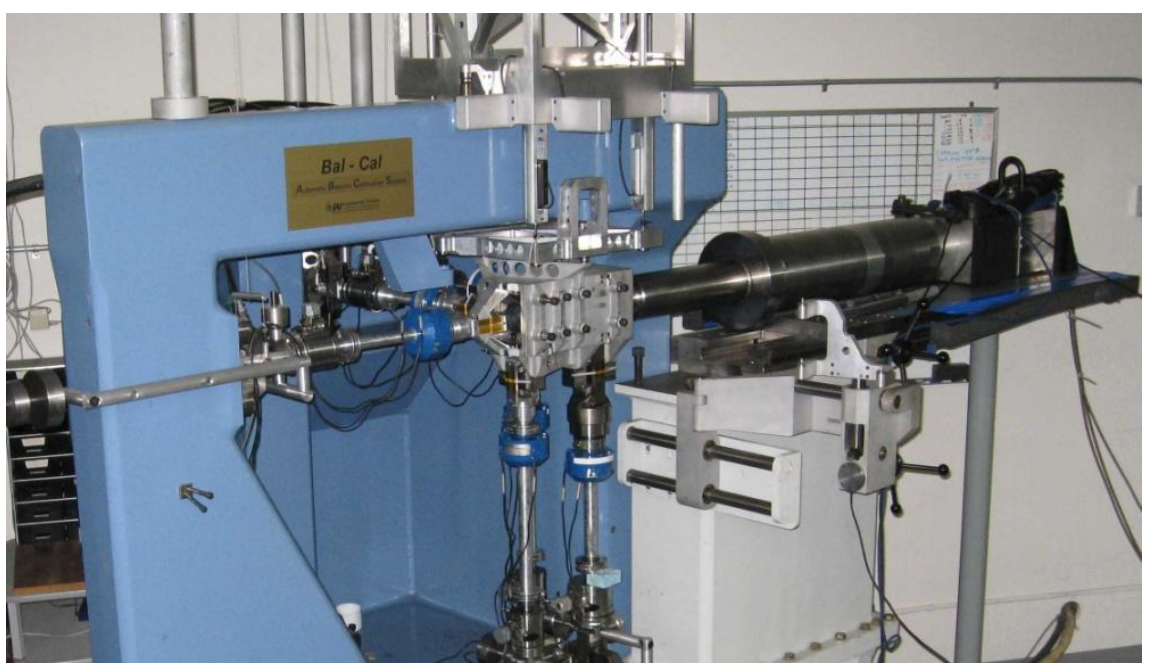

Fig 3. Jet Exit Rig Balance in the ABCS.

Flow Conditioning Station

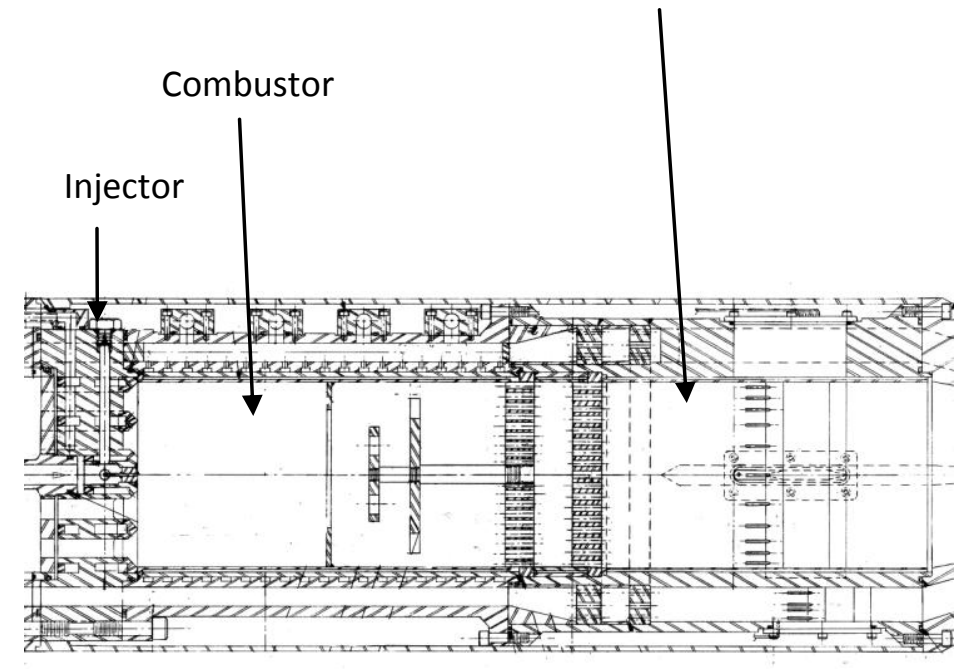

(a)

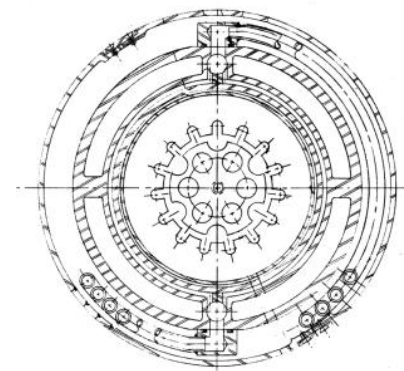

(b)

Fig 4. (a) Jet Exit Rig Combustor, (b) Cross Section Through Baffles. 


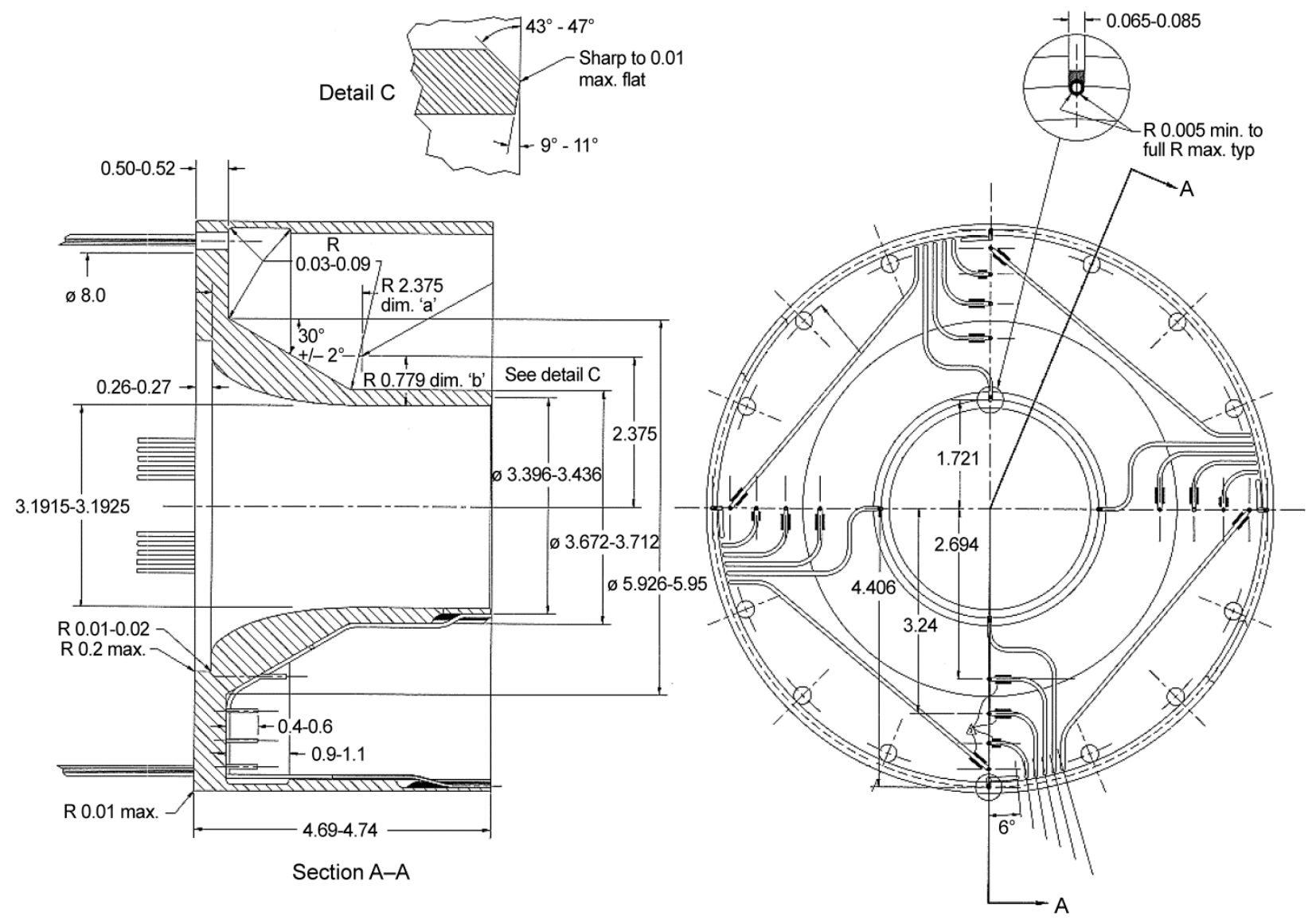

Fig. 5. ASME Nozzle. 


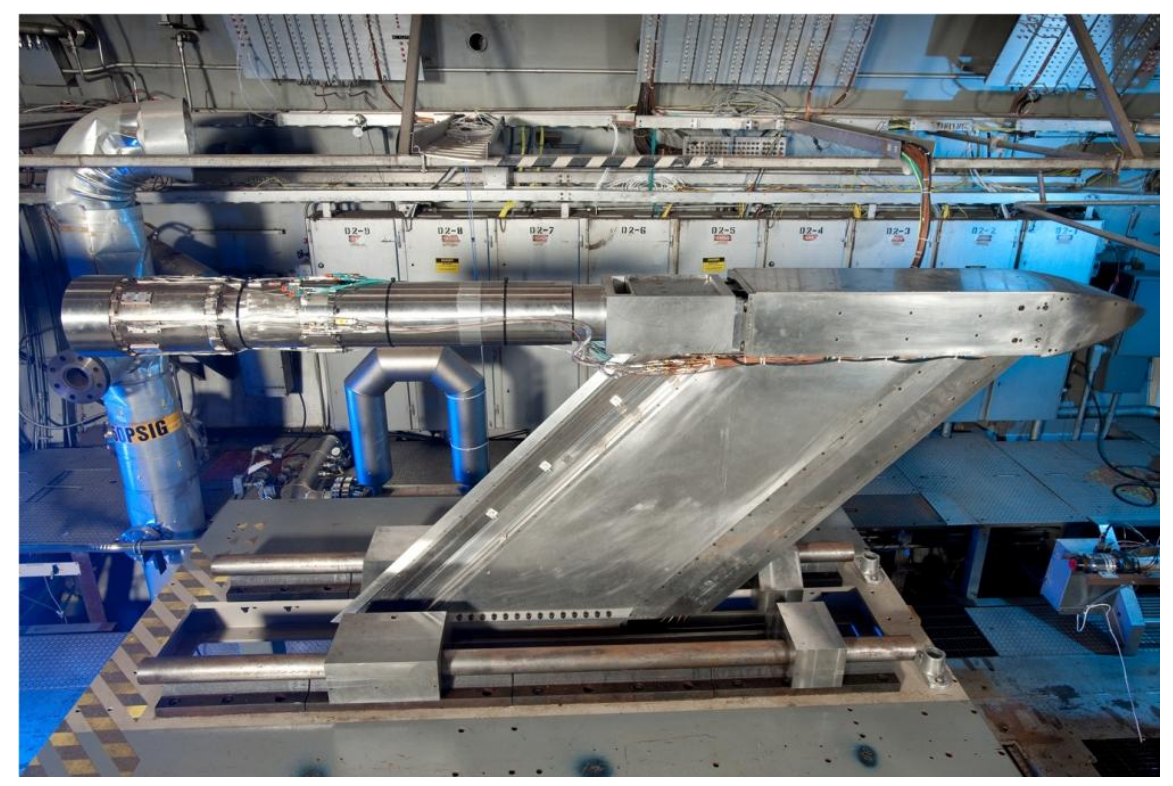

Fig. 6. Jet Exit Rig in Propulsion Systems Lab at NASA GRC (side view).

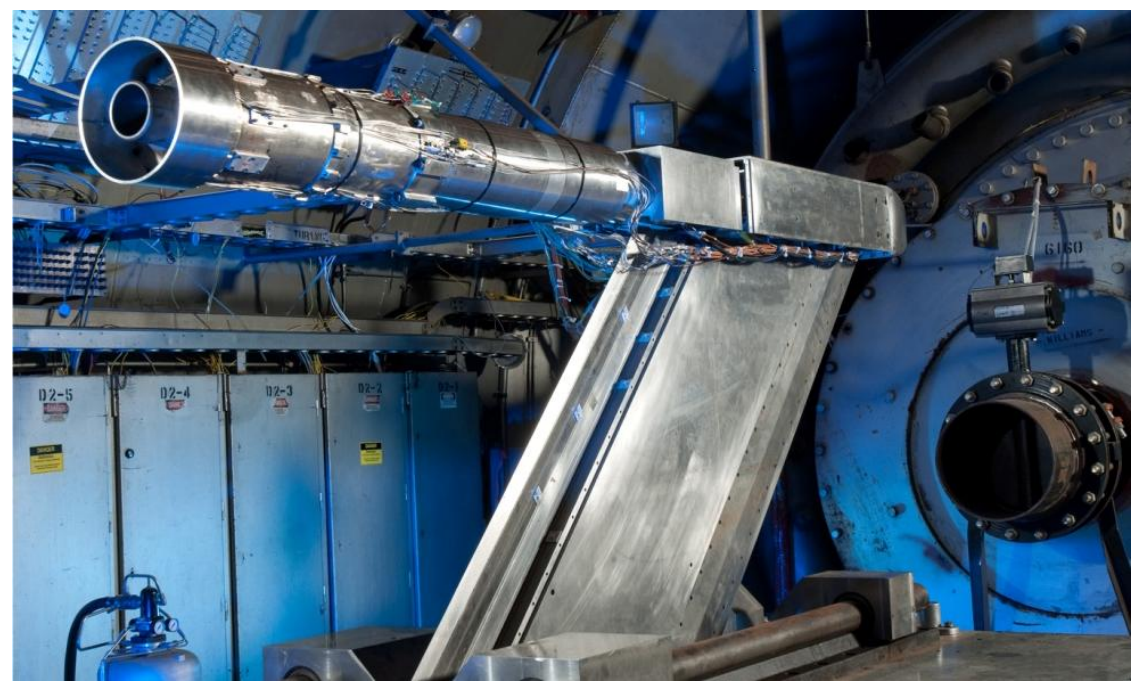

Fig. 7. Jet Exit Rig in Propulsion Systems Lab at NASA GRC (aft view). 


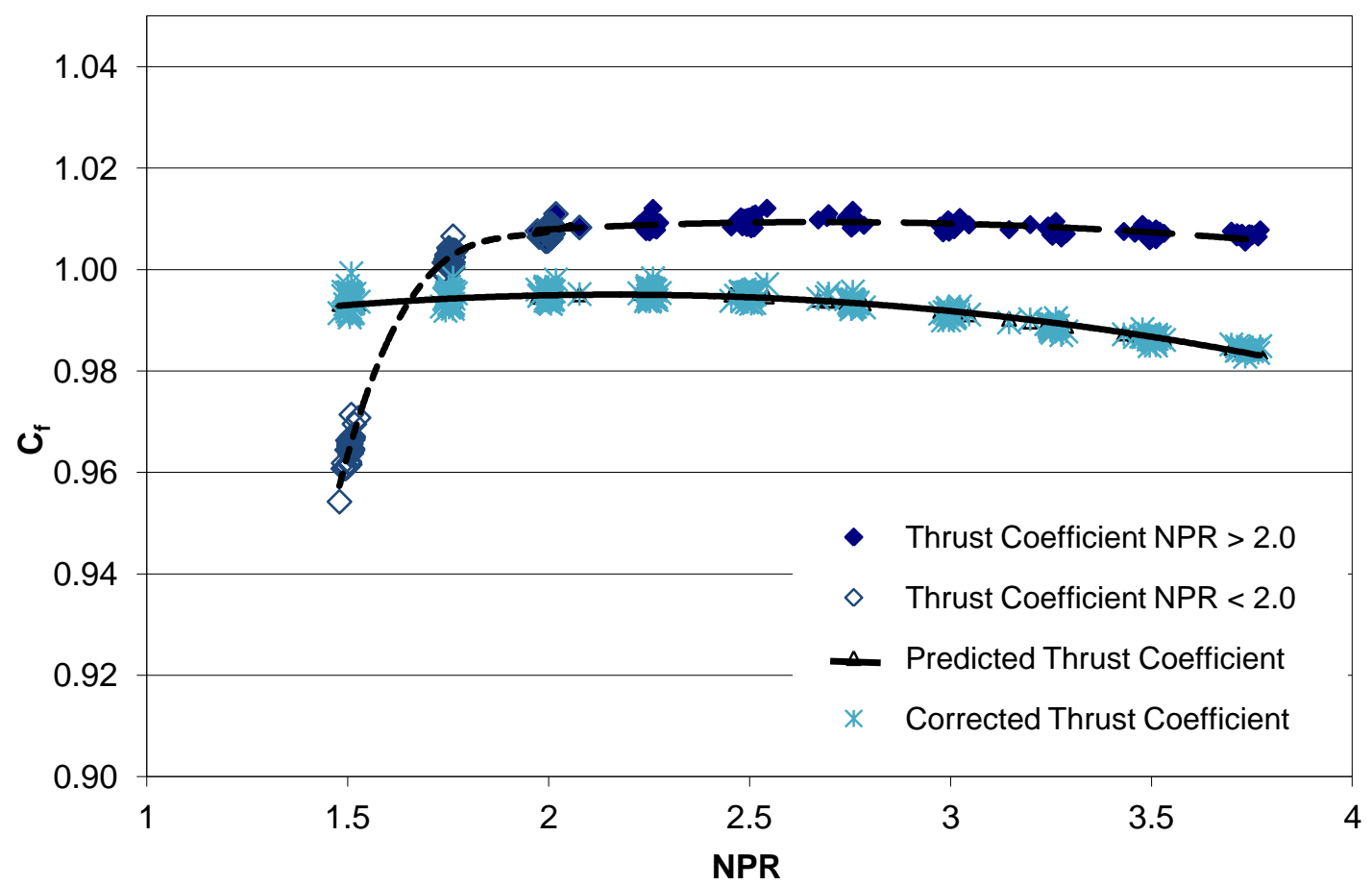

Fig. 8. Jet Exit Rig Force Balance ASME Nozzle Thrust coefficient.

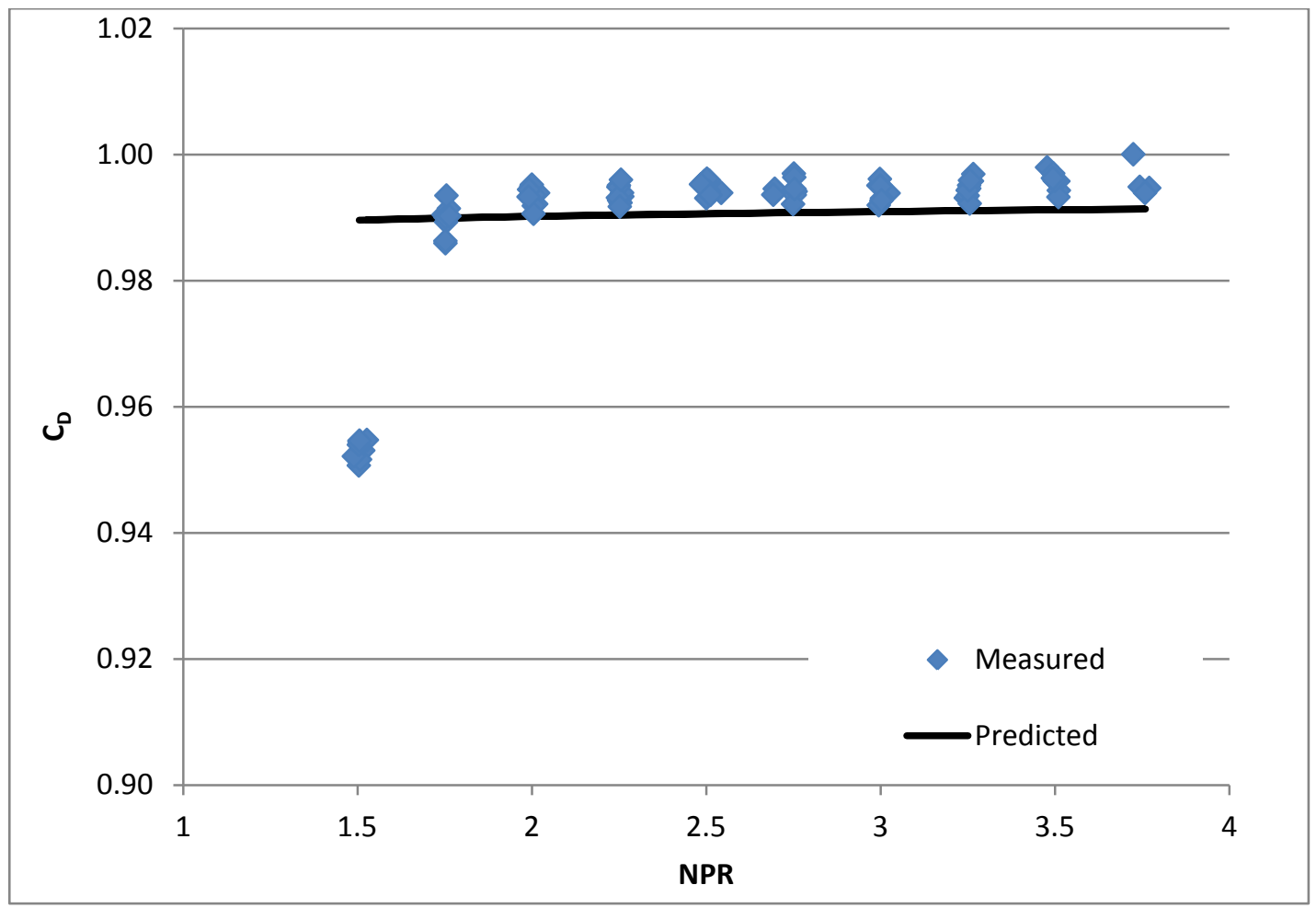

Fig. 9. Jet Exit Rig Force Balance Nozzle Discharge Coefficient. 